\title{
Elderly Patients with Pertrochanteric Hip Fracture: In Hospital Care
}

\author{
Faour Martín 0*, Valverde García JA, Sáez López, Martín Ferrero \\ and Vega Castrillo A \\ Complex Hospital of Avila-sacyl, Orthopaedic Surgery and Traumatology Service, \\ University of Valladolid, Spain
}

*Corresponding author: Omar F Martín, Complex Hospital of Ávila-Sacyl,

Research Article

Volume 3 Issue 4

Received Date: November 19, 2019

Published Date: December 16, 2019

DOI: $10.23880 /$ jobd-16000190

Orthopaedic Surgery and Traumatology Service, Spain, Tel: 0034-630081151; Email: ofmartin@msn.com

\section{Abstract}

Objective: To evaluate the improvement in the care of elderly patients hospitalized due to pertrochanteric hip fractures.

Methods: A comparative study of two cohorts of patients admitted due to pertrochanteric hip fracture before (2010) and after the application of in hospital management protocols (2018). The intervention consisted in the implementation of multidisciplinary measures during hospitalization based on current scientific evidence. An evaluation of the clinical results was performed, as well as the health care impact.

Results: The characteristics of patients admitted for hip fracture in 2010 (216 patients) and 2018 (205 patients) were similar in age, sex, Barthel index and the Charlson abbreviated index. In 2018 patients had more comorbidity. A significant reduction of preoperative stay and overall stay in the cohort of 2018 was achieved. Detection of delirium, malnutrition and anaemia was higher in 2018, and a reduced incidence of infection and a better functional efficiency was achieved in this period.

Conclusion: The introduction of measures for the improvement of the pertrochanteric hip fracture management reduces hospitalization with consequent cost reduction. Unification of criteria among professionals may be an opportunity for better clinical results and reduction of complications.

Keywords: Hip; Pertrochanteric; Fracture; Elderly patient; Management

\section{Introduction}

Pertrochanteric hip fracture is a common pathology in the elderly population and has significant comorbidity and mortality rates [1]. In Spain there are around 40,000 pertrochanteric hip fractures per year [2]. It is estimated that the incidence rate will double by 2050 [3]. The described mortality rate one year after the lesion in the elderly is around $30 \%$, with less than $50 \%$ of the cases recovering the functional capacity prior to the fracture [35]. The time elapsed from admission to surgery has implications for global hospitalization time. In-hospital organizational problems and medical comorbidities of patients are two of the main reasons for surgical delay [6]. The cost of treatment of pertrochanteric hip fracture is high mainly in relation to the acute phase of 


\section{Journal of Orthopedics \& Bone Disorders}

hospitalization and surgical treatment, with an estimated price in the European Union of between 5,000 and 9,000 euros [4].

There is an association between a worse functional recovery, a higher rate of comorbidities and longer stays, with surgical delay.

In Spain, the average in-hospital mortality during admission due to pertrochanteric hip fracture is 5.3\% $[7,8]$. Our main objective is to present the comorbidity data in the in-hospital management of patients with pertrochanteric fracture, before and after the establishment of multidisciplinary medical protocols in this regard.

\section{Methods}

A longitudinal comparative study of two cohorts of patients affected by pertrochanteric hip fracture was carried out. The admitted patients in 2010 constituted the control group, and on patients admitted in 2018 new multidisciplinary medical protocols for in-hospital management were used.

The criteria considered for the selection of the patients were: patients with pertrochanteric hip fracture, with an age equal to or greater than 75 years, excluding those patients with pathological fractures or those who presented high energy trauma. In 2010, 216 patients were admitted, in which no established protocol was applied.

In 2018, 205 patients were admitted, and they constituted the intervention group in which the new measures of medical protocols for in-hospital management were applied.

For the study of the patients the following data were collected: clinical and functional history, epidemiological information on admission, degree of dependence and functional capacity, pharmacological treatments, complications and mortality during admission, existence or not of surgical delay and its cause, epidemiological information on discharge, and existence or not of change of destination of the patient after discharge.

The in-hospital management of patients admitted during 2018 due to pertrochanteric hip fracture was carried out following various multidisciplinary protocols, according to the scientific evidence in this regard [9].
These points of improvement in patient care covered the following aspects:

- Antibiotic Prophylaxis: Preoperative antibiotic prophylaxis was performed in all patients. A single preoperative dose of Cefazoline 2 gr. was used. In case of allergy to Bethalactamics, Vancomicine 2 gr. was used.

- Oxygen Therapy: In all patients, nasal glasses were used at 3 liters per minute in the preoperative period and during the first 48 hours postoperatively. Oxygen therapy is subsequently maintained if the oxygen saturation was less than $90 \%$.

- Thromboprophylaxis: Preoperative low molecular weight heparin was used, with treatment suspension 12 hours before surgery and reintroduction 12 hours after surgery. In patients with renal dysfunction, heparin was withdrawn 24 hours before surgery.

- Analgesia: Parenteral regimen of paracetamol alternating with metamizol was used, with a rescue dose of tramadol if needed, in the preoperative time and the first postoperative day. During the second day of the postoperative period, oral analgesia administration was indicated.

- Management of the Antiplatelet/Anticoagulated Patient: Establishment of minimum waiting times to surgery from the administration of the antiaggregant: five-days for clopidogrel and between two and three days for the new oral anticoagulants according to renal function, while acetylsalicylic acid does not need to wait. In relation to acenocumarol, surgical waiting is reduced using $\mathrm{K}$ vitamin, until normalization of the INR.

- Surgical Priority: Elderly patients with hip fracture were a surgical priority, and the necessary means and infrastructure must be sought to carry out the surgery in the first hours after the injury.

- Delirium: If the patient is diagnosed with dementia or has delirium since admission, treatment was prescribed, if possible orally, with risperidone $0.5 \mathrm{mg} /$ $12 \mathrm{~h}$. Without the history of dementia and without delirium, risperidone was prescribed $0.5-1 \mathrm{mg}$ if agitation.

- Anemia: Transfusion indication of two red blood cell concentrates with hemoglobin $(\mathrm{Hb})$ levels less than or equal to $8 \mathrm{gr} / \mathrm{dl}$. If the $\mathrm{Hb}$ figure is greater than $10 \mathrm{gr} /$ $\mathrm{dl}$, transfusion is not required. With $\mathrm{Hb}$ levels between 8 and $10 \mathrm{gr} / \mathrm{dl}$, transfusion is indicated if the patient has cardiac insufficiency, respiratory or cerebral ischemia. In the case of $\mathrm{Hb}$ between 8 and $10 \mathrm{gr} / \mathrm{dl}$, with no indication of transfusion, sucrose iron $200 \mathrm{mg}$ iv / 3 times per week (600 in total) was used. 


\section{Journal of Orthopedics \& Bone Disorders}

- Rehabilitation: In the postoperative period, the sitting was performed within the first 24 hours and the standing started between 36 and 48 hours according to the patient's tolerance. The re-education of the march was carried out with the help of the Rehabilitation Service.

- Malnutrition: If the patient presented nutritional risk or malnutrition, (score greater than 3 on the Nutritional Risk Scale), protein supplements were prescribed.

- Social Risk: In a multidisciplinary way, the geriatric, traumatology and nursing services carried out an assessment of the patient's social situation from the moment of admission, coordinating with the social workers the necessary resources in this regard.

The treatment of the personal data required in this study complies with the Spanish Law of Protection of Personal Data 03/2018, of December 5.

The descriptive analysis consisted in the study of the means and standard deviations for the quantitative variables, and of the proportions for the qualitative ones. Bivariate analysis was performed to compare the groups. To know the pattern of relationship between the variables, the t-Student test and the $\chi 2$ test (Chi square) with Yates correction if necessary were used. Statistical analysis was performed with the SPSS (C) version 16 program (SPSS Inc., Chicago, IL). Throughout the statistical analysis, the existence of statistically significant differences was assumed when a value of $p<0.05$ was obtained.

\section{Results}

The analysis of the epidemiological variables did not reveal the existence of significant differences between the groups of patients admitted in 2010 and in 2018 in relation to age and sex (Table 1 ). The most predominant origin of the patients was from the private home in both groups, but with a greater presence in the group of the year 2010 of patients from family home. We found no differences in the preoperative Charlson and Barthel index between the two periods, with the most frequent comorbidities being dementia, cardiovascular pathology and diabetes mellitus. The surgical treatment used in all cases was the proximal femoral nailing. The type of anesthesia most used was the spinal one in the two groups, with no differences in this regard $(p=0.706)$.

During admission (Table 2), significant differences were found between the groups in the diagnoses of anemia, delirium and malnutrition, more frequent in the 2018 patient group; on the other hand, the incidence of surgical infection was higher in the 2010 group. The overall mean hospital stay showed a significant difference from 16.5 days in 2010 to 9.3 days in 2018.

\begin{tabular}{|c|c|c|c|}
\hline Variable & 2010 n (\%) & 2018 n (\%) & Value $p$ \\
\hline Patients (nํㅜ) & 216 & 205 & \\
\hline Age (SD) & $87,26(5,76)$ & $85,18(5,82)$ & 0,057 \\
\hline Sex & & & 0,125 \\
\hline -Males & $38(17,59)$ & $47(23,98)$ & \\
\hline -Females & $178(82,41)$ & $149(76,02)$ & \\
\hline Provenance & & & 0,009 \\
\hline -Family & $65(30,10)$ & $33(16,09)$ & \\
\hline -Individual & $78(36,11)$ & $95(46,34)$ & \\
\hline -Residency & $73(33,79)$ & $77(37,56)$ & \\
\hline Deambulation & & & 0,427 \\
\hline -Autonomous & $62(28,71)$ & $51(24,87)$ & \\
\hline -With help & $145(67,13)$ & $142(69,26)$ & \\
\hline -No deambulation & $9(4,16)$ & $12(5,85)$ & \\
\hline Barthel Index. Media (DE) & $64,86(25)$ & $65,13(27)$ & 0,983 \\
\hline Comorbidity & $214(99,07)$ & $205(100)$ & 0,50 \\
\hline Number of comorbidities. Mean (SD) & $5,59(3,04)$ & $5,72(3,4)$ & 0,115 \\
\hline Charlson Index. Mean (SD) & $1,63(1,2)$ & $1,78(1,2)$ & 0,361 \\
\hline with $\geq 3$ & $49(22,68)$ & $51(24,87)$ & 0,410 \\
\hline \multicolumn{4}{|c|}{ Anaesthesic Risk ASA } \\
\hline -III-IV & $177(81,94)$ & $140(71,42)$ & 0,563 \\
\hline
\end{tabular}




\section{Journal of Orthopedics \& Bone Disorders}

\begin{tabular}{|c|c|c|c|}
\hline- I-II & $39(18,06)$ & $56(28,58)$ & \\
\hline $\begin{array}{c}\text { Surgical treatment } \\
\begin{array}{c}\text { No surgical treatment possible (no suitable } \\
\text { anesthesia) }\end{array}\end{array}$ & $196(90,74)$ & $186(91,77)$ & 0.664 \\
\hline Anesthetic technique & & $19(-8.23)$ & 0.764 \\
\hline Spinal & $165(-84.18)$ & $171(-91.9)$ & 0.165 \\
\hline General & $31(-15.8)$ & $15(-8.1)$ & \\
\hline
\end{tabular}

Table 1: Baseline characteristics of the patients.

In relation to the surgical delay, the number of patients waiting for surgery for more than 72 hours decreased by almost 15\% from 2010 to 2018 (Table 2) . The mean reason for the delay in 2018 was the lack of operating room available or admission during weekend (Figure 1).

The hospital mortality was $9.26 \%$ in the case of the group of patients of the year 2010 and $6.52 \%$ in the group of 2018, without significant differences $(p=0.265)$. The functional capacity at discharge, including the variable hospital stay duration as a correction factor, presented significant favorable results in the group of patients of the year $2018(p=0.000)$. The number of drugs at discharge was similar in both groups. Differences were found regarding the number of patients treated for osteoporosis at discharge, which is much higher in $2018(\mathrm{p}=0.00)$. There were no differences in terms of institutionalization or change of habitual residence. The analysis of the entire group of patients showed that the surgical delay was significantly associated with a greater overall stay $(\mathrm{p}=$ 0.000 ), with a greater number of complications during hospitalization $(\mathrm{p}=0.022)$ and a greater number of drugs at discharge $(p=0.023)$. Likewise, it was observed that the number of complications was related with a high number of comorbidities and with a delay in surgery exceeding 72 hours $(\mathrm{p}<0.005)$.

\begin{tabular}{|c|c|c|c|}
\hline Variable & $\mathbf{2 0 1 0} \mathbf{n ~ ( \% )}$ & $\mathbf{2 0 1 8} \mathbf{n}(\mathbf{\%})$ & Signification (p< 0,05) \\
\hline № complications >=2 & $109(50,5)$ & $173(83,9)$ & 0,00 \\
\hline Cardiovascular & $60(27,77)$ & $49(25,51)$ & $>0.05$ \\
\hline Respiratory & $39(18,05)$ & $27(14,79)$ & $>0.05$ \\
\hline Surgical wound infection & $14(6,48)$ & $5(2,04)$ & 0,031 \\
\hline Urinary infection & $12(5,55)$ & $14(8,67)$ & 0.05 \\
\hline Anemia & $174(80,55)$ & $181(95,41)$ & 0,002 \\
\hline Delirium & $78(36,11)$ & $101(53,00)$ & 0,001 \\
\hline Malnutricion & $24(11,11)$ & $52(28,57)$ & $>0.05$ \\
\hline Pressure ulcers & $12(5,55)$ & $10(5,10)$ & $>0.05$ \\
\hline Renal insufficiency & $51(23,61)$ & $47(-22.83)$ & $>0.05$ \\
\hline Thromboembolic disease & $6(2,77)$ & $4(-1.95)$ & $>0.05$ \\
\hline Hidroelectrolytic & $41(18,98)$ & $42(-20.48)$ & $>0.05$ \\
\hline Diabetes decompensation & $22(10,18)$ & $17(-8.29)$ & $>0.05$ \\
\hline Mortality & $20(9,26)$ & $13((6,12))$ & $>0.05$ \\
\hline Transfusion & $114(65,51)$ & $104((56,15))$ & 0,004 \\
\hline Intravenous iron & $0(0)$ & $47(24)$ & $>0.05$ \\
\hline No drugs at discharge. Mean (SD) & $7,53(3,1)$ & $8,80(3,09)$ & 0,002 \\
\hline Osteoporosis treatment (\%) & $29(14,80)$ & $140((76,09))$ & 0,001 \\
\hline Preoperative hospital stay. Mean (SD) & $6,23(3,3)$ & $3,2(2,3)$ & 0,001 \\
\hline Global hospital stay. Mean (SD) & $16,61(8,1)$ & $9,08(3,9)$ & 0,005 \\
\hline Surgical delay n (\%) & $163(83,16)$ & $118(68,40)$ & 0,012 \\
\hline Destination to discharge & & & \\
\hline -Home address & $54(27,55)$ & $62(30,43)$ & $>0.05$ \\
\hline -Family address & $59(30,10)$ & $33(16,09)$ & \\
\hline -Residency & $83(42,34)$ & $97(47.31)$ & \\
\hline Change of location & $29(14,79)$ & $39((20,11))$ & \\
\hline
\end{tabular}




\section{Journal of Orthopedics \& Bone Disorders}

\begin{tabular}{|c|c|c|c|}
\hline Institucionalization & $21(10,7)$ & $31(15,2)$ & $>0.05$ \\
\hline Barthel Index on Admission & 64,86 & 65,14 & $>0.05$ \\
\hline Barthel Index at discharge & 31,35 & 37,72 & $>0.05$ \\
\hline Eficiencia funcional. Mean (SD) & $4,21(3,6)$ & $7,56(4,4)$ & 0 \\
\hline
\end{tabular}

Table 2: Clinical comparation of both groups (2010 / 2018).

\section{REASONS OF SURGICAL TREATMENT DELAY > 72 HOURS \%}

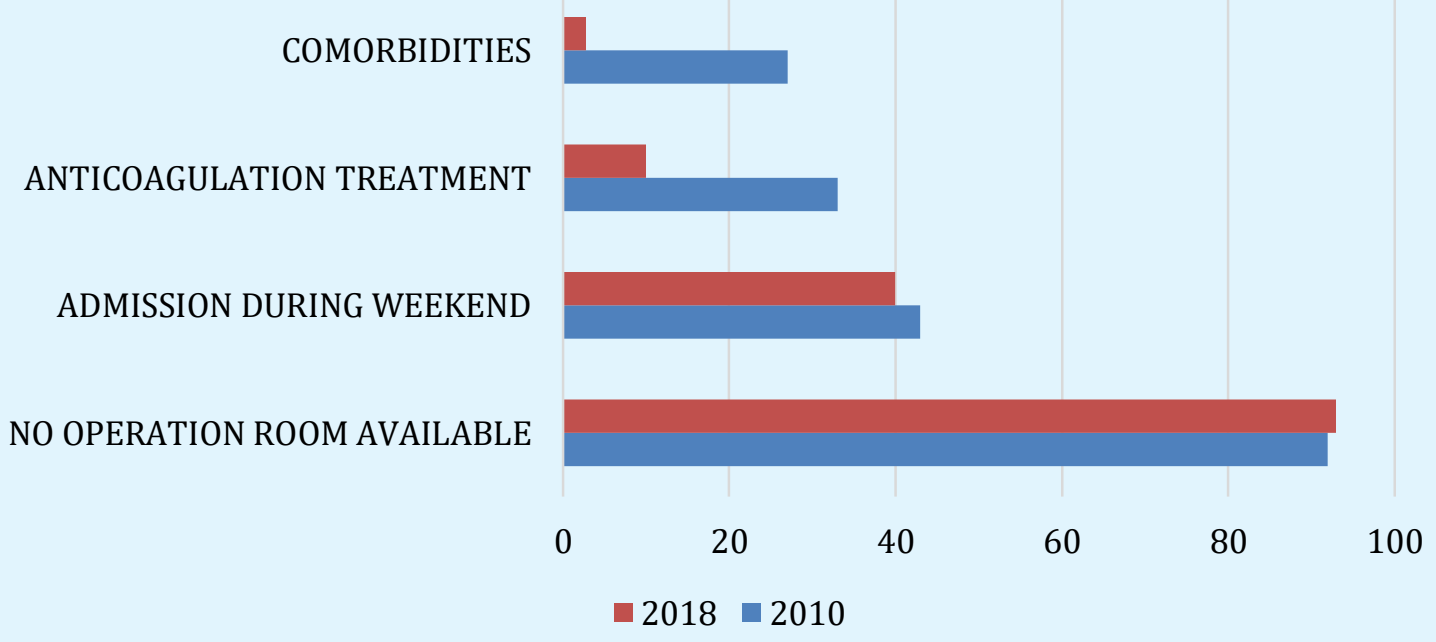

Figure 1: Reasons of surgical treatment delay.

\section{Discussion}

The studied patients have on average a number of comorbidities that far exceeds that registered in other similar series [11,12]. In this regard, it is worth mentioning dementia (present in $42 \%$ of patients in 2010 and $47 \%$ in the 2018 group), followed by cardiovascular pathology and diabetes. González Montalvo [13] collected the prevalence of other diseases in patients admitted due to hip fracture obtained by various series, registering a percentage of arterial hypertension of $29-47 \%$, dementia of $8-36 \%, 8-40 \%$ of ischemic heart disease, $7-23 \%$ of diabetes, cancer disease of 5-13\%, Parkinson's of $4-8 \%$ and $3-18 \%$ of renal failure, among others. The patients in this study took an average of six drugs, with a polypharmacy percentage of $60 \%-70 \%$, a figure higher than that recorded in other publications $[4,14]$.

During the acute phase of a hip fracture, between 15 and $30 \%$ of patients present serious complications, registering a great variability in the frequency of some authors to others [15-17]. Our patients had a higher average of complications in 2018. The fact that health personnel have been trained in the detection of them through the implementation of protocols may influence the greater registration of complications in the group of patients of the year 2018. In the analysis of all the patients we have found that the number of complications was associated with a high number of comorbidities (Charlson index greater than three and more than five comorbidities), including dementia, the degree of dependence on admission (Barthel index) and the delay in surgery exceeding 72 hours $(p<0.005)$. Postoperative anemia was, with a percentage of around $95 \%$, the most frequent complication in 2018, finding statistically significant differences compared to the 2010 group ( $p=$ 0.00 ). Despite this, the number of patients treated with blood transfusion was lower in the 2018 group. 


\section{Journal of Orthopedics \& Bone Disorders}

Delirium is detected more frequently in our group of 2018 (53\%) than in 2010 and with similar percentages to other studies of the literature [18]. The improvement in the detection and treatment of delirium, included in the nursing registry, is related to an early detection. The same explanation may be the case of malnutrition, with percentages in 2018 exceeding 28\%, comparable to those of other works [19] and much lower than in 2010. The lower proportion of surgical wound infection was registered in the 2018 group, with a significant difference from 2010. It should be noted that the percentage of this complication in the two periods studied is lower than in other series $[6,11]$. Several factors may have influenced this result. We highlight the implementation of an antibiotic prophylaxis protocol, reviewed in 2017, the early detection and treatment of malnutrition and the lower number of transfusions, all of which are related to increased infections. The results are consistent with the intervention performed, since the training of personnel in the revised protocols allows improving the detection and treatment of complications [20].

In Spain, hospital mortality in elderly people with hip fracture is around 5\% [5]. In our study, in-hospital mortality frequencies in the acute phase were greater, $9.26 \%$ and $6.12 \%$ in the 2010 and 2018 groups, respectively. There are numerous factors that influence hospital mortality, making comparison between studies difficult. Factors that contribute to a lower percentage of hospital mortality in previous studies $[6,21,22]$ are the inclusion of younger patients, the exclusion of preoperative deaths and patients with non-surgical treatment with a short hospital stay. The meta-analysis published by $\mathrm{Hu}$, et al. [23] analyzes preoperative mortality predictors and concludes that among the 12 most potent are the high number of comorbidities and preoperative dementia. In this aspect, in the two years studied, a high number of previous comorbidities were obtained (between five and six), with a percentage of dementia of $42 \%$ and $48 \%$, respectively, all factors related to increased hospital mortality.

On the other hand, this work has included people older than 75 years old, non-surgical treatments and deaths prior to surgery, which may have contributed to the result of higher mortality (excluding the last two, hospital mortality drops to $5.1 \%$ in 2010 and to $2.87 \%$ in 2018). The average time of admission in pur study has been reduced comparing the year 2010 with 2018 . Literature described the improvement in the rates of total hospital stay depending on the type of geriatric assistance between five and nine days $[12,13,24]$. The average preoperative stay in Spanish hospitals is around 4.31 days $[5,25]$. In our revision, the waiting time until surgery has been significantly reduced in the group of 2018 in 1.83 days. This data has been improved with the new planning of the scheduled surgical activity and the establishment of a higher priority for hip fracture surgery. It has been the lack of operating room availability, as in other studies [6], with figures greater than $90 \%$ in the two periods, the most frequent cause of surgical delay. Analyzed all the patients of our study, a relationship has been established between surgical delay and the number of complications, the increase in drugs at discharge and the total hospital stay. There is a discrepancy in the literature about the association between surgical delay and mortality. In fact, prospective and retrospective studies conclude that there is no relationship between presurgical stay and one-year mortality $[6,26]$, although they recommend early surgery in order to avoid medical complications and improve patient comfort. On the other hand, when an adjustment is made for age, sex and comorbidity, others authors showed that the delay of more than 48 hours from the moment of admission to the hospital leads to an increase in mortality at six months and one year $[27,28]$.

In our data, almost $6 \%$ more patients in the 2018 group change their location at discharge. The change is that fewer patients go to the family home and more patients go to residences, probably influenced by the new family structure, with less support for the dependent ancient. The absence of a Functional Recovery Unit as a specific geriatrics resource means that the only options available are the return to the home or the ancient's residency [29]. Many times, the absence of centers to which patients can be referred after the acute phase avoids early discharge [30]; however, in our experience it has been possible to reduce the overall stay of the intervention group, sometimes using the only recourse available (ancients residences) [29]. Both groups studied were discharged with a higher prescription of drugs than in the period prior to admission. This data may reflect the ability of geriatrics to detect a greater number of new diagnoses and reduce the incidence of complications that go unnoticed during the time of admission, which justifies the increase in the number of drugs at discharge. These therapies include, as in other studies [14,19], the highest degree of treatment for secondary prevention of osteoporosis.

Among the limitations of this study, the possibility of information biases can be considered. Since the variables used have been recorded from the clinical history of each patient, the quality of the completion of the same could 


\section{Journal of Orthopedics \& Bone Disorders}

have a different impact. To avoid it as much as possible, electronic and paper-format documentation have been used, which has helped to improve data recording. As advantages, the update on clinical problems is pointed out by the researchers themselves and by the collaborative group, provoking a consensus to improve patient care. The descriptive nature of the study prevents establishing causal relationships, although the consistency of the results with other studies of similar characteristics supports the coherence of the findings.

The establishment of a quality improvement plan, agreed upon among all the professionals involved in the hip fracture process, contributes to unifying criteria, determines opportunities for improvement and can achieve beneficial effects comparable to the organization in an orthogeriatrics unit. Among the benefits, this work finds a reduction in hospital stay, with the consequent reduction in costs and greater detection of complications, which allows them to be treated more efficiently, without negative repercussion at the clinical, functional or survival level.

\section{References}

1. Parker M, Johansen A (2016) Clinical Review: Hip fracture. BMJ 333(7557): 27-30.

2. Herrera A, Martínez A, Ferrández L, Gil E, Moreno A (2016) Epi-demiology of osteoporotic hip fractures in Spain. Int Ort-hop 30(1): 11-14.

3. Gullberg B, Johnell O, Kanis JA (1997) World-wide proyections for hip fracture. Osteoporosis Int 7(5): 407-413.

4. Ortiz Alonso FJ, Vidán Astíz M, Marañón Fernández E, Ál-varez Nebreda L, García Alambra MA, et al. (2018) Evolución prospectiva de un programa de intervención geriátrica interdisciplinaria y secuencial en la recupera-ción funcional del anciano con fractura de cadera. Trauma Fund Mapfre 19(1): 13-21.

5. Instituto de Información Sanitaria (2010) Estadísticas comentadas: la atención a la fractura de cadera en los hospitales del SNS. [Statistical report: the care of hip fracture in Spanish National Health Service hospitals]. Spanish Ministry of Health and Social Policy, Madrid.

6. Vidán M, Sánchez E, Gracia Y, Marañón E, Vaquero J, et al. (2011) Causes and effects of surgical delay in patients with hip fracture: a cohort study. Ann Intern Med 155(4): 226-233.
7. González Montalvo JI, Alarcón T, Hormigo Sánchez AI (2011) ¿Por qué fallecen los pacientes con fractura de cadera? Med Clin (Barc) 137(8): 335-360.

8. Siegmeth A, Gurusamy K, Parker M (2015) Delay to surgery pro-longes hospital stay in patients with fractures of proximal femur. J Bone Joint Surg $(\mathrm{Br})$ 87(8): 1123-1126.

9. Bardales Mas Y, González Montalvo JI, Abizanda Soler P, Alarcón MT (2012) Guías clinicas de fractura de cadera. Comparación de sus principales recomendaciones. Rev Esp Geriatr Gerontol 47(5): 220-227.

10. Sáez López P, Valverde García JA, Faour Martín O, Sán-chez Hernández N (2013) Estrategias de tratamiento en la fractura de cadera del anciano. Madrid: Egraf S.A.

11. Sáez López P, Madruga Galán F, Rubio Caballero JA (2007) De-tección de problemas en paciente geriátrico con fractura de cadera. Importancia de la colaboración entre traumatólogo y geriatra. Rev Ortop Traumatol 51(3): 144-151.

12. Bielza Galindo R, Ortiz Espada A, Arias Muñana E, Velas-co Guzmán R (2013) Implantación de una unidad de ortogeriatría de agudos en un hospital de segundo nivel. Rev Esp Geriatr Gerontol 48(1): 26-29.

13. González Montalvo JI, Gotor Pérez P, Martín Vega A, Alar-cón Alarcón T, Mauleón Álvarez de Linera JL, et al. (2011) La unidad de ortogeriatría en agudos. Evaluación de su efecto en el curso clínico de los pacientes con fractura de cadera y estimación de su impacto económico. Rev Esp Ge-riatr Gerontol 46(4): 193-199.

14. Sáez López P, González Montalvo JI, Alarcón T, Madruga F, Barcena A (2006) Optimización del tratamiento médico en pa-ciente geriátrico con fractura de cadera. Influencia del equi-po consultor. Rev Esp Geriatr Gerontol 41(2): 85-91.

15. Gdalevich M, Cohen D, Yosef D, Tauber C (2004) Morbidity and mortality after hip fracture: the impact of operative delay. Arch Orthop Trauma Surg 124(5): 334-340.

16. Hirose J, Ide J, Irie H, Kikukawa K, Mizuta H (2018) New equa-tions for predicting postoperative risk in patients with hip fracture. Clin Orthop Relat Res 467(12): 3327-3333. 


\section{Journal of Orthopedics \& Bone Disorders}

17. Sáez López P (2002) Estudio sobre la intervención geriátrica en la fase aguda de los pacientes geriátricos que ingresan por fractura de cadera [thesis doctoral]. Madrid. Universidad Complutense de Madrid.

18. Gotor P, González Montalvo JI, Alarcón T (2014) Factores asocia-dos a la aparición de delirium en pacientes geriátricos con fractura de cadera. Rev Mult Gerontol 14(3): 138-148.

19. Chong CP, Savige JA, Lim WW (2010) Medical problems in hip fracture patients. Archives of Orthopaedic and Trauma Sur-gery 130(11): 13551361.

20. Menzies IB, Mendelson DA, Kates SL, Friedman SM (2012) The impact of comorbidity on perioperative outcomes of hip fractures in a geriatric fracture model. Geriatr Orthop Surg Rehabil 3(3): 129-134.

21. Peralta Vargas CE (2013) Factores asociados a la recuperación de la marcha y la funcionalidad en ancianos hospitalizados por fractura de cadera [thesis doctoral]. Universidad Complutense de Madrid, Madrid.

22. Navarrete FE, Fenollosa B, Jolín T (2010) Factores de riesgo de mortalidad al año en pacientes no intervenidos. Trauma Fund MAPFRE 21(3): 219-223.

23. Hu F, Jiang C, Shen J, Tang P, Wang Y (2012) Preoperative pre-dictors for mortality following hip fracture surgery: a systematic review and metaanalysis. Injury 43(6): 676-685.

24. Álvarez de Arcaya VM, Veras Sanz J, Varea K, Ariztia Sa-rratea M, Alderete Díez C, et al. (2012) Improving healthcare efficiency with coordination between levels of care: orthogeriatrics. Int J Integrat Care 12: 30-35.

25. Sáez López P, Martín Pérez E, González Ramírez A, Pablos Hernández C, Jiménez Mola S, et al. (2014) Actividad ortogeriátrica en los hospitales públicos de Castilla y León: descripción y revisión de la literatura. Rev Esp Ge-riatr Gerontol 49(3): 137-44.

26. Librero J, Peiro S, Leutscher E, Merlo J, BernalDelgado E, et al. (2012) Timing of surgery for hip fracture and in-hospital mortality: a retrospective population-based cohort study in the Spanish National Health System. BMC Health Services Research 12: 15-20.

27. Simunovic N, Devereaux PJ, Sprague S, Guyatt GH, Sche-mitsch E, et al. (2010) Effect of early surgery after hip fracture on mortality and complications: systematic review and meta-analysis. CMAJ 182(15): 1609-1616.

28. Shiga T, Wajima Z, Ohe Y (2008) Is operative delay associated with increased mortality of hip fractured patients? Systema-tic review, meta-analysis, and metaregression. Can J Anesth 55(3): 146-154.

29. Sáez López P, Hernández Jiménez T, Romero Mayoral I (2013) Deterioro funcional secundario a fractura de cadera y ade-cuación de recursos sociosanitarios al alta. Rev Esp Geriatr Gerontol 48(2): 98-99.

30. Pearse M, Woolf A (1992) Care of elderly patients with a fractu-res neck of femur. Hlth Treds 24(4): 134-136. 